\title{
Measuring potential output for the South African economy: Embedding information about the financial cycle
}

HARRI KEMP

Stellenbosch Economic Working Papers: 03/14

KEYWORDS: POTENTIAL OUTPUT, OUTPUT GAP, FINANCIAL CYCLE, MONETARY POLICY

JEL: E10, E40, E44, E47, E52

HARRI KEMP

DEPARTMENT OF ECONOMICS BUREAU FOR ECONOMIC RESEARCH UNIVERSITY OF STELLENBOSCH PRIVATE BAG X1, 7602

MATIELAND, SOUTH AFRICA

E-MAIL: JHKEMP@SUN.AC.ZA 


\title{
Measuring potential output for the South African economy: Embedding information about the financial cycle
}

\author{
HARRI KEMP
}

\begin{abstract}
In a recent paper, Borio et al (2013a) show that information embedded in the financial cycle can serve to improve measures of potential output and output gaps. It is argued that output may be on an unsustainable path despite low and stable inflation if financial imbalances are accumulating. Borio et al (2013a) show that incorporating information on the financial cycle yields measures of potential output and output gaps for the US, UK and Spain that are estimated more precisely and are more robust in real time. With its well-developed financial markets and relatively open capital markets, the South African economy is potentially susceptible to the build-up of the sort of financial imbalances that characterised the recent financial crisis. However, existing measures of the output gap for South Africa do not generally incorporate information on the financial cycle. Using the framework developed in Borio et al (2013a), a finance-neutral measure of the output gap is estimated for South Africa. The traditional HP-filter is extended to incorporate information on credit and property prices. Including financial cycle proxies result in output gaps that are estimated more precisely and are more robust to data revisions and the arrival of new data points (i.e. estimated output gaps are more robust in real time), while also reflecting the impact of financial variables on economic activity. As such, the estimated financeneutral output gap seems to represent a more appropriate measure on which to base monetary policy decisions than the traditional inflation-neutral measures prevalent in the literature.
\end{abstract}

Keywords: Potential output, output gap, financial cycle, monetary policy JEL codes: E10, E40, E44, E47, E52 


\section{Contents}

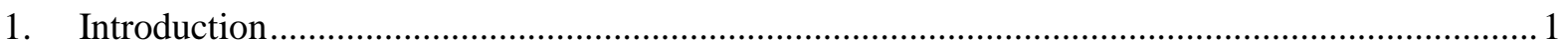

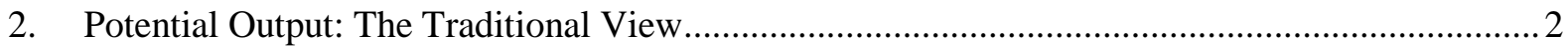

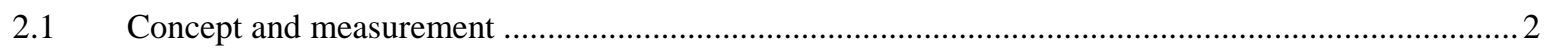

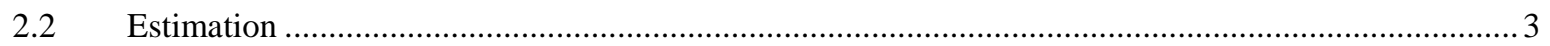

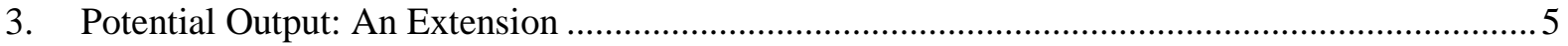

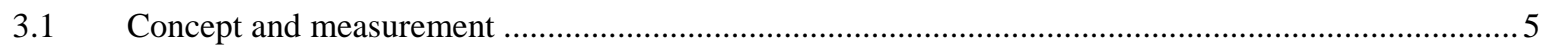

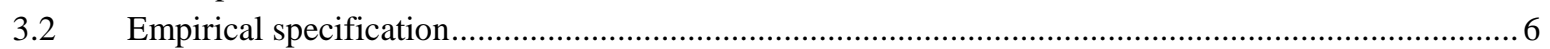

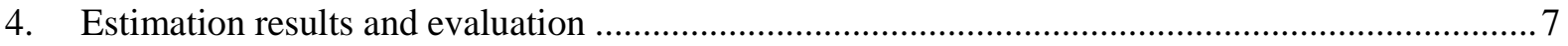

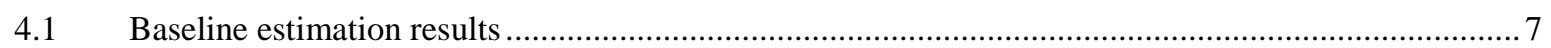

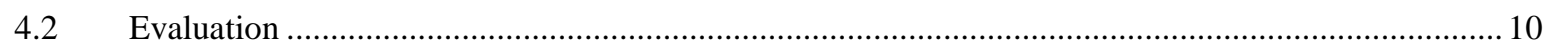

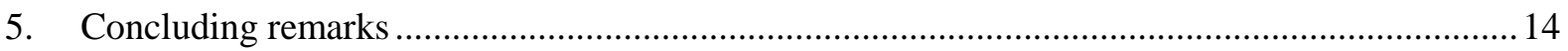

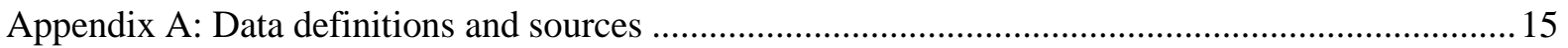

Appendix B: HP-filter and Unobserved Components............................................................................. 16

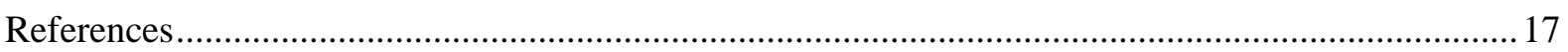

\section{List of figures}

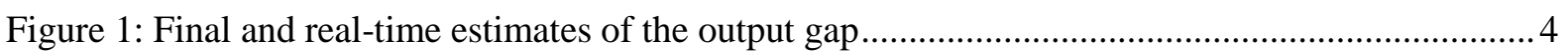

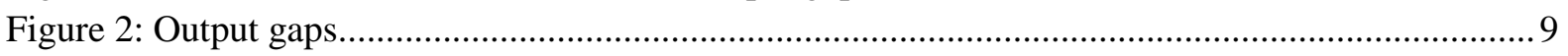

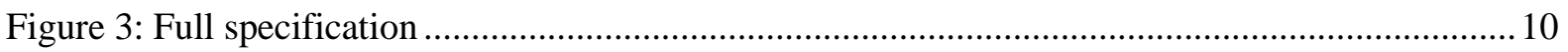

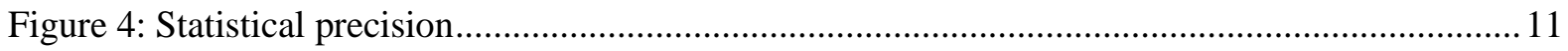

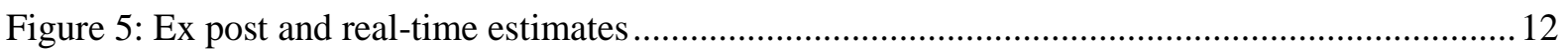

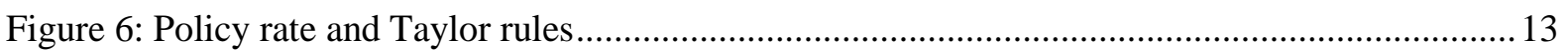

\section{List of tables}

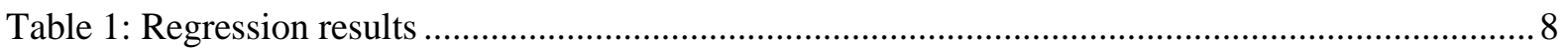




\section{Introduction}

Measuring potential output accurately is important. Judgements about the stance of the economy, medium term growth prospects and policy analysis depend on it. Over the medium term, the growth rate in potential output provides a guide for the assessment of sustainable non-inflationary growth in output and employment. The deviation of actual from potential output - the so-called output gap provides a measure of aggregate demand pressure relative to potential in an economy at a particular time. The output gap therefore contains useful short-term information for the formulation of economic policy, specifically stabilisation policy.

But potential output is hard to measure. Firstly, potential output is unobservable. Numerous concepts have been defined in the literature, but no consensus has been reached on the precise definition of potential output. Secondly, given the difficulty in pinning down a precise definition of potential output, a wide variety of methods are used in estimation exercises. Estimation results are often quite sensitive to the specific method employed and are in general not robust across methodologies.

Potential output is most often associated with some concept of sustainable factor utilisation and is often linked to inflationary pressure. It is generally accepted that inflationary pressure rises when output is above potential and vice versa when output falls below potential. As such, inflation in particular is viewed as a key symptom of unsustainability. However, thinking of potential output only as non-inflationary output is too restrictive. Recent history has shown that other imbalances, notably in the financial sector and in asset markets, can emerge while inflation remains low and stable. Research has shown that financial factors contain important information relevant to the cyclical component of output. In particular, Borio, Disyatat and Juselius (2013a), henceforth BDJ, show that embedding financial sector information in a flexible estimation framework results in an improvement in the reliability and accuracy of real-time output gap estimates for the US, UK and Spain.

With its well-developed financial markets and relatively open capital markets, the South African economy is potentially susceptible to the build-up of the sort of financial imbalances that characterised the recent financial crisis ${ }^{1}$. This possibility motivates the application of BDJ's method in the South African case. The most widely used statistical approach for estimating potential output, the HP-filter, is extended to incorporate information on the financial cycle. Information on credit and property prices is incorporated into the estimation of potential output in order to account for the potential build-up of imbalances on financial markets. Similar to BDJ, estimation results show that incorporating financial cycle information (as captured by the behaviour of credit and property prices) yields a measure of the output gap that is estimated much more precisely and, importantly, is more robust in real time.

The rest of the paper is organised as follows. Section 2 reviews concepts of potential output in the existing literature and prevailing measurement approaches. Section 3 discusses the proposed extension in which financial factors play an important role in identifying cyclical fluctuations in output and outlines the empirical model used in the estimation. Section 4 presents baseline estimation results and evaluates the resulting finance-neutral output gap measure in terms of statistical precision, performance in real time and the implications for monetary policy. Section 5 concludes.

\footnotetext{
${ }^{1}$ In the wake of the global financial crisis attention turned to the US as a prime example of the unsustainable build-up of imbalances on financial markets. However, in the decade preceding the crisis, potential imbalances were also building in the South African market - real credit extended to the private sector grew by an average $11 \%$ per annum between 2003 and 2007, while real property prices grew by $14 \%$ per year over the same period.
} 


\section{Potential Output: The Traditional View}

\subsection{Concept and measurement}

A precise definition of potential output has been hard to pin down. Taken literally, potential output refers to the maximum possible output of an economy if all resources were fully employed. Alternatively, the term could refer to some "normal" level of production given average or trend factor utilization rates. The definition most commonly used in recent studies, however, identifies potential output as the maximum level of output attainable without generating an increase in inflation (Gibbs, 1995).

The measurement of potential output is far from straightforward. Potential output can be derived from either a purely statistical approach or from full econometric analysis. The former attempts to separate a time series (such as real GDP) into trend and cyclical components using identifying assumptions based on purely statistical considerations, while the latter attempts to isolate the effects of structural versus cyclical influences on output using economic theory.

The simplest statistical detrending technique is the linear time trend method ${ }^{2}$. The linear time trend method builds on the assumption that a series can be decomposed into a linear deterministic trend component and a cyclical component. This was the standard assumption until the early 1980's. However, several time series studies in the 1980's (see for example Nelson and Plosser, 1982) came to the conclusion that many macroeconomic time series - including GDP - contain a unit root or stochastic trend. This implies that the trend component in GDP is subject to irregular stochastic shocks, which may have a permanent effect on the level of GDP. Consequently, if deterministic trends are used in order to calculate potential output and/or output gaps, there is a risk that stochastic trend elements may not be completely eliminated (McMorrow and Roeger, 2001). Under these circumstances, the linear time trend method is misspecified and overestimates output gaps by partially attributing trend components to the cyclical component.

The Hodrick-Prescott (HP) filter (Hodrick and Prescott, 1997) attempts to overcome the above mentioned shortcoming of the linear time trend method and has become a popular detrending technique in the literature and at policy institutions ${ }^{3}$. As with the linear time trend method, the idea behind the HP-filter is to decompose a series into a trend component and cyclical component and utilises a long run, symmetric, moving average technique to achieve the decomposition. The properties and shortcomings of the HP-filter are well documented (eg. Harvey and Jaeger, 1993; StAmant and Van Norden, 1997; Cerra and Saxena, 2000; McMorrow and Roeger, 2001; Mise, Kim and Newbold, 2003). Major drawbacks include the difficulty in identifying the appropriate detrending parameter, high end-sample bias (which reflects the two-sided moving average approach), the possibility of inducing spurious cyclicality when applying the filter to integrated or near-integrated series and excessive smoothing of structural breaks.

An alternative, albeit somewhat more complex, method to the above filtering techniques is the Kalman filter/unobserved components approach (Kalman, 1960; Harvey, 1992). When interested in decomposing individual series (such as GDP) into trend and cycle components within a univariate framework, the components can be recovered from the observed series by imposing sufficient restrictions on the trend and cycle and making assumptions about the functional form of these

\footnotetext{
${ }^{2}$ See Akinboade et al (2004) for an application to South Africa.

${ }^{3}$ See Smit and Burrows (2002), Arora and Bhundia (2003) and Akinboade et al (2004), among others, for an application to South Africa.
} 
components as well as the structure of the error processes. A multivariate extension is also possible which allows for additional information to assist the decomposition process (Benes and N'Diaye, 2004; Cotis et al, 2005; Konuki, 2008).

Structural econometric techniques for estimating potential output include the popular production function approach, the structural VAR (SVAR) approach and, more recently, the estimation of trend output utilising estimates obtained from dynamic stochastic general equilibrium (DSGE) models ${ }^{4}$.

The general philosophy underlying the SVAR approach to estimating potential output rests on the theoretical idea that demand shocks are transitory, while supply shocks permanently affect output (i.e. affects output in the long run). The original Blanchard and Quah (1989) decomposition stems from the traditional Keynesian and neoclassical synthesis which identifies potential output with aggregate supply capacity and cyclical fluctuations with changes in aggregate demand ${ }^{5}$. By imposing various long run restrictions on a system in output and other relevant variables (such as inflation and/or the real exchange rate), structural supply disturbances can be recovered after which the path of potential output can be derived using the resulting vector of supply shocks ${ }^{6}$.

More recently, a new approach to measuring potential output has emerged, which is based on NewKeynesian Dynamic Stochastic General Equilibrium models (Vetlov et al, 2011). It allows for the estimation of various alternative model-based measures of potential output, encompassing the level of output obtained under flexible prices and wages. However, measures of potential output obtained from DSGE models are dependent on the underlying characterisation of the economy employed in the specific modelling exercise. Changes in the underlying characterisation can lead to substantially different estimates of potential output across models.

\subsection{Estimation}

As a baseline result, output gap estimates obtained from two of the abovementioned standard estimators, namely the HP-filter and unobserved components (UC), are presented below. See Appendix B for more details on these particular estimators. Quarterly expenditure on GDP at constant prices (seasonally adjusted and annualised) was used as the measure for real GDP. See Appendix A for detailed information on data sources and definitions.

To compare the performance of the standard estimators with that of the alternative estimator suggested in BDJ and applied in this paper, both real-time and final output gap estimates were generated. In order to facilitate the real-time estimation of output gaps, a dataset for real GDP constructed by Kramer and Farrell (2013) was used. The first vintage of the data is the December 1981 Quarterly Bulletin as published by the South African Reserve Bank (SARB). It contains data on GDP from 1960Q1 to 1981Q3 and will be referred to as 1981Q4 for short. The final vintage of data is 2013Q3, which was the most recent vintage at the time of the study. Altogether, there are 128 vintages over the period 1981Q4 to 2013Q3.

\footnotetext{
${ }^{4}$ See Smit and Burrows (2002), Arora and Bhundia (2003), Du Toit et al (2006) and Akinboade et al (2004) for an application of the production function approach; and Arora and Bhundia (2003) and Du Plessis et al (2007) for an application of the SVAR approach to South Africa.

${ }^{5}$ An alternative decomposition is the one proposed by Beveridge and Nelson (1981). They proposed that the long-run forecast is a measure of trend for time series such as GDP that do not follow a deterministic path in the long run. In contrast to many of the approaches listed, the Beveridge-Nelson decomposition attributes most of the variation in time series to trend shocks while cycles are assumed to be short and brief.

${ }^{6}$ The analysis can be extended in various ways. For example, one can include temporary nominal shocks by including a price variable affected by these nominal shocks in the short and long run (see Clarida and Gali, 1994)
} 
Real-time output gap estimates are constructed by detrending each vintage in the real-time dataset and collating the most recent estimate from each vintage. For example, the output gap series estimated from the 2010Q2 vintage would provide the real-time estimate for 2010Q1. The final estimate is generated by detrending the most recent vintage, in this case 2013Q2. A comparison of the final and real-time estimates then reveals the extent to which the output gap estimates have been revised in each point in time.

Both the real-time and final output gap estimates obtained using the two standard techniques mentioned above are given in Figure $1^{7}$. The shaded areas represent official downswings as published by the SARB.

Figure 1: Final and real-time estimates of the output gap
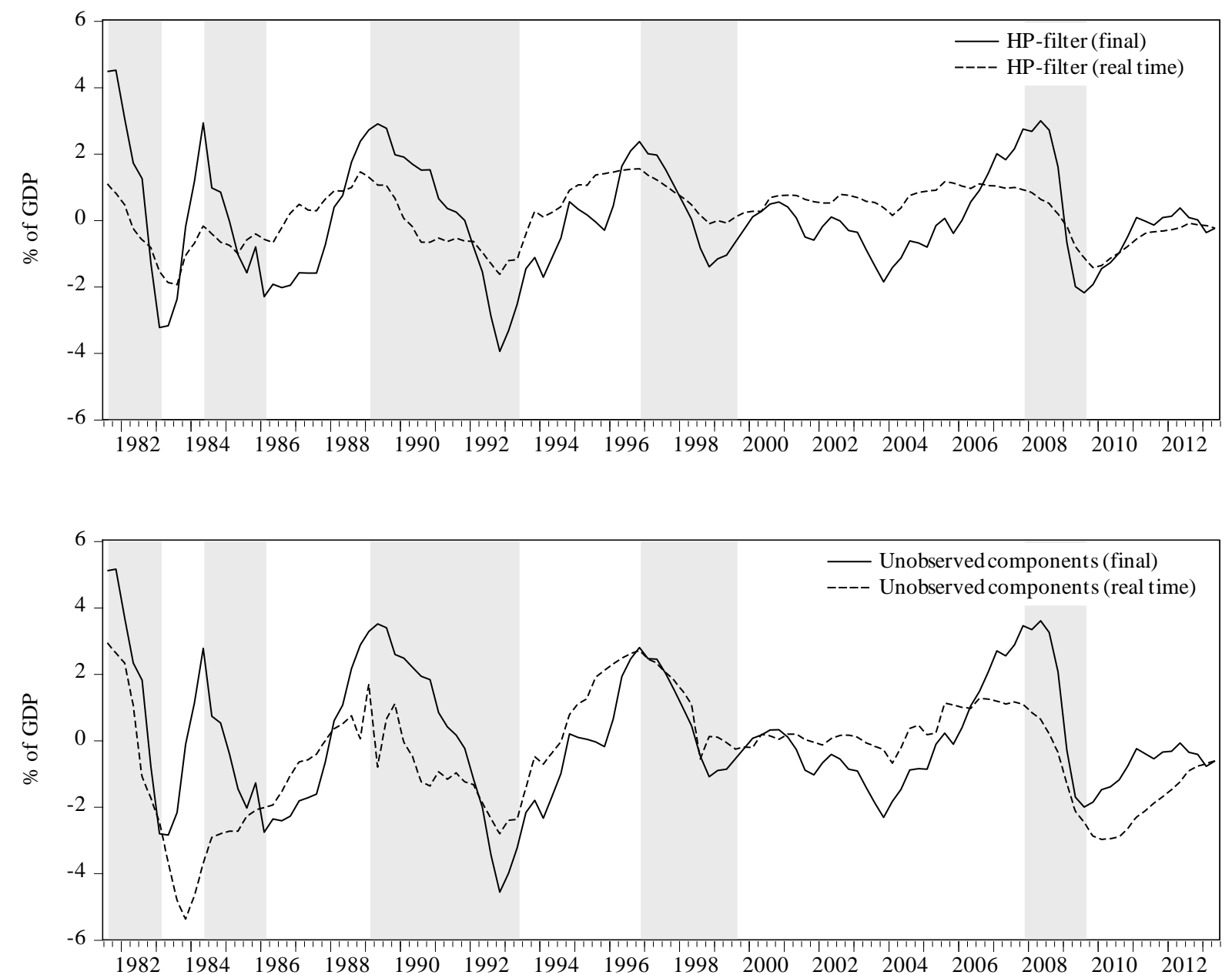

A comparison between the different estimates presented in Figure 1 reveals several interesting characteristics. Firstly, the final output gap estimates obtained from both the standard HP-filter and the UC model display broadly similar patterns across the sample. Both manage to reflect official business cycle turning points as published by the SARB quite closely.

\footnotetext{
${ }^{7}$ In an attempt to alleviate the end-point bias inherent in the HP- filter, each GDP vintage is augmented with a forecast of 25 observations using an AR(4) process. This is in line with the recommendations of, among others, Kaiser and Maravall (1999) and Mise et al (2005).
} 
Secondly, despite similar cyclical patterns in the final estimates, the different methods do not produce output gaps of similar size. In fact, the output gap estimates obtained from the UC model are on average 0.4 of a per cent larger (in absolute terms) than those obtained from the HP-filter. This highlights one of the difficulties in estimating potential output and the output gap - the end result is highly dependent on the choice of estimation method.

Lastly, it is clear from the figures above that the final estimate of the output gap (obtained from the final vintage of GDP data) differs quite starkly from the real-time estimates. In fact, it would appear that the real-time South African output gap estimates are quite unreliable and undergo significant revisions over time. This can partly be ascribed to revisions in national accounts data, including GDP $^{8}$. However, as noted in Kramer and Farrell (2013), the major driver is the availability of new data points over time and highlights the unreliability of end-point estimates for the standard filtering techniques. Given the fact that policy decisions are made in real-time, based on the data available at a particular point in time, the unreliability of real-time estimates of the output gap makes policy making all the more fraught. Policy actions that may seem perfectly reasonable and appropriate might prove to be wholly inappropriate as new data become available. For example, based on the real-time estimates in Figure 1 monetary policy might well have been too tight in the early 2000s and, conversely, too loose in the years directly preceding the financial crisis.

The estimator presented in this paper results in a more precise final estimate, as well as significant improvements in real-time estimates for the South African output gap. The latter might prove useful in the policy arena. The next section discusses the extended concept of potential output as suggested by $\mathrm{BDJ}$ and presents the specification of the empirical model used in the estimation exercise.

\section{Potential Output: An Extension}

\subsection{Concept and measurement}

The traditional view of potential output can be linked to the broader literature on the relation between internal and external equilibrium. Meade (1978) discusses the ways in which policymakers could act to achieve both internal balance (i.e. price stability and full employment) and external equilibrium (i.e. balance-of-payments equilibrium). The notion of internal balance is neatly captured in the traditional view which of potential output as non-inflationary (or at least inflation-neutral) and as the embodiment of full and/or sustainable factor utilisation.

However, thinking of potential output only in non-inflationary terms might be too restrictive. It is possible for output can be on an unsustainable path while inflation remains low and stable as financial imbalances build up. BDJ identify at least four reasons for this being the case. Firstly, strong financial booms often coincide with positive supply shocks, which put downward pressure on prices. Secondly, the economic expansion itself might weaken supply constraints. For example, a prolonged expansion could increase labour supply, either through increased labour participation or immigration. Thirdly, financial booms are often associated with an appreciation in the currency as domestic assets become more attractive and capital flows surge, putting downward pressure on inflation. Lastly, the unsustainability of output might have more to do with sectoral misallocation of resources than with

\footnotetext{
${ }^{8}$ National accounts data are subject to regular minor revisions, as well as more comprehensive revisions that occur once every few years. Comprehensive revisions seek to accommodate a number of improvements such as changes in the classification of variables, improvements in methodology and/or rebasing exercises (Kramer and Farrell, 2013).
} 
overall capacity constraints. The relevant sectors are often particularly sensitive to credit developments (i.e. real estate).

Given the concerns raised above, measures of potential output that ignore financial factors can be particularly misleading. In fact, any concept of internal balance that ignores the role of financial markets is incomplete. Economic activity may appear robust, but financial and real developments might mask the underlying vulnerabilities that eventually lead to the bust. The recent financial crisis is a particularly stark example.

The above discussion highlighted the importance of taking into account the extent to which financial conditions constrain or support economic activity when formulating judgements about the sustainability of the current growth path. The approach followed in BDJ and applied here to South Africa attempts to capture the informational content that financial variables have for the cyclical component of output, in the process arriving at more robust estimates of sustainable (or potential) output. This finance-neutral measure of potential output contrasts with the more traditional inflationneutral measures prevalent in the literature.

BDJ take the HP-filter as a point of departure in specifying the empirical model used to estimate a finance-neutral measure of potential output. One reason for this is that the HP-filter approach to measuring potential output is very familiar and free of strong economic assumptions. To facilitate easy comparison with measures in the existing literature, it is assumed that the smoothing parameter lambda is equal to 1600 . The traditional HP-filter is then extended to include information on financial cycles in a way that does not impose strong priors on the data. This is achieved by recasting the HPfilter in state space and adding additional variables to the observation (or measurement) equation. This method contrasts with the more popular approach of embedding an inflation relationship (i.e. an inflation Phillips curve) into a system of equations, which forces the behaviour of inflation to be driven by the output gap. Instead, the data are allowed to determine whether or not financial variables contain information on the cyclical component of output.

The next section discusses the empirical specification in more detail.

\subsection{Empirical specification}

The HP-filter can be cast in state-space form by specifying the state and measurement equations as

$$
\begin{aligned}
& \Delta y_{t}^{*}=\Delta y_{t-1}^{*}+\varepsilon_{0, t} \\
& y_{t}=y_{t}^{*}+\varepsilon_{1, t}
\end{aligned}
$$

where $y_{t}=\ln \left(Y_{t}\right), Y_{t}$ is real GDP and $\varepsilon_{i, t}$ for $i=0,1$ is assumed to be a normally and independently distributed error with mean zero and variance $\sigma_{i}^{2}$. For a given state equation (such as (1) above), the so-called signal-to-noise ratio (defined as $\lambda_{1}=\sigma_{1}^{2} / \sigma_{0}^{2}$ ) determines the relative variability of the estimated potential output series. When $\lambda_{1}$ is very large, potential output approximately follows a linear trend; when $\lambda_{1}$ approaches zero, potential output mimics actual output. As a baseline, this parameter is set so that the duration of the estimated output gap is at most eight years and implies a value for $\lambda_{1}$ of 1600 in a quarterly sample.

Borio et al (2013b) show that a robust way of embedding economic information in output gap estimates is to augment (2) with additional variables, i.e.

$$
y_{t}-y_{t}^{*}=\gamma^{\prime} x_{t}+\varepsilon_{2, t}
$$


where $x_{t}$ is a vector of economic variables, possibly containing lags of the output gap itself. In order to preserve the same duration of the business cycle as implied by the standard HP-filter when moving from (2) to (3), BDJ use a state equation of the form (1) and set the signal-to-noise ratio $\lambda_{2}=\sigma_{2}^{2} / \sigma_{0}^{2}$ such that

$$
\operatorname{var}\left(y_{t}-y_{(2), t}^{*}\right) / \operatorname{var}\left(\Delta^{2} y_{(2), t}^{*}\right)=\operatorname{var}\left(y_{t}-y_{(3), t}^{*}\right) / \operatorname{var}\left(\Delta^{2} y_{(3), t}^{*}\right)
$$

where $y_{(2), t}^{*}$ and $y_{(3), t}^{*}$ are the potential output estimates obtained from (2) and (3) respectively. Setting $\lambda_{2}$ such that condition (4) holds implies a relative volatility of potential output that is comparable to that obtained from the standard HP-filter.

The approach based on (1) and (3) represents a compromise between theory and statistics in estimating potential output ${ }^{9}$. The advantage of the approach lies in the fact that standard estimators of the parameters in (3) will assign a zero weight to any information in $x_{t}$ that does not help in explaining business cycle fluctuations. This contrasts to other semi-structural methods for estimating potential output (such as multivariate filters) which embed economic relationships (such as a New Keynesian Phillips curve) in a system of equations framework and force the output gap to explain the associated variables (in this case inflation).

Several specifications of (3) are considered. Following BDJ, two particular types of financial variables are investigated: private sector credit and property prices, here only residential house prices ${ }^{10}$. Additionally, an autoregressive component for the output gap is added in an attempt to capture output gap dynamics. Equation (3) then becomes:

$$
y_{t}-y_{t}^{*}=\beta\left(y_{t-1}-y_{t-1}^{*}\right)+\gamma_{1} r_{t-k_{r}}+\gamma_{2} \Delta c r_{t-k_{c}}+\gamma_{3} \Delta p p_{t-k_{p}}+\varepsilon_{3, t}
$$

where $r_{t}=i_{t}-\Delta p_{t}$ is the ex post real interest rate, $\Delta p_{t}$ is consumer price inflation, $\Delta c r_{t}$ is real credit growth in per cent and $\Delta p p_{t}$ is residential property price growth in per cent ${ }^{11}$. All variables are meanadjusted $^{12}$. All variables are allowed to enter only once, with the lags $k_{j}=0, \ldots, 4, j=r, c r, p$ chosen to maximise statistical fit.

\section{Estimation results and evaluation}

\subsection{Baseline estimation results}

Estimation is carried out over the quarterly sample 1970Q1 - 2013Q2. Appendix A contains detailed information on data sources and definitions. To estimate (5), a conventional Bayesian approach is adopted. Prior distributions for the parameters are specified, after which the posterior density function is maximised with respect to these parameters using the Kalman filter. The IRIS toolbox add-on to

\footnotetext{
${ }^{9}$ Should the real interest rate be included in $x_{t}$, equation (3) resembles an extended IS-curve. This is consistent with theoretical work by Woodford (2012) who shows that financial frictions would generally show up in the IS-curve in a New Keynesian framework.

${ }^{10}$ This is consistent with the empirical literature highlighting the informational content of credit and property prices for business cycles and financial crises (e.g. Borio and Lowe, 2002; Alessi and Detken, 2009; Aikman et al, 2011; Borio, 2012; Drehmann et al, 2012).

${ }^{11}$ As in BDJ. several additional variables were tested in (5), including HP-filtered real interest rates, inflation (both mean adjusted and HP trend-adjusted), equity prices as measured by the JSE ASI and the log real effective exchange rate. None were significant at the $5 \%$ level.

${ }^{12}$ As most of the variables display a high degree of cyclicality, their means are estimated using Cesàro averages as in BDJ. This produces faster convergence and reduces pro-cyclicality in the mean-adjustment. See Borio et al (2013b) for a detailed discussion.
} 
Matlab was used in the estimation exercise. Importantly, $\beta$ is restricted to lie between 0 and 0.95 . The upper bound is chosen so as to avoid unit-root output gaps. In each case, $\lambda_{2}$ is set such that (4) is satisfied.

Table 1: Regression results

\begin{tabular}{cccccc}
\hline Model & 1 & 2 & 3 & 4 & 5 \\
\hline \multirow{2}{*}{$\beta$} & 0.95 & 0.93 & 0.89 & 0.90 & 0.87 \\
& $(-)$ & $(22.2)$ & $(26.0)$ & $(24.3)$ & $(23.8)$ \\
$r_{t-4}$ & - & -0.05 & - & - & - \\
& & $(-1.8)$ & & & \\
$\Delta c r_{t}$ & - & - & 0.13 & - & 0.11 \\
& & & $(5.3)$ & & $(4.3)$ \\
$\Delta p p_{t-2}$ & - & - & - & 0.09 & 0.06 \\
\hline
\end{tabular}

Note: Estimated maximum posterior modes with associated t-values in parenthesis; due to data restrictions model (2) is only estimated for the period 1982Q1 to 2013Q2.

In order to assess the effect that each variable taken in isolation has on the estimated output gap, (5) is successively estimated with only one explanatory variable at a time. Table 1 gives the estimated coefficients, with corresponding t-values in parenthesis. Figure 2 gives a visual presentation of the estimated output gaps in each of the models (1) to (4). Following BDJ, the models are referred to as interest-, credit- and property price neutral respectively.

As is clear from Table 1, the estimated output gaps are highly persistent and close to unit root processes - the coefficient on the lagged output gap, $\beta$, ranges between 0.87 and 0.95 . When modifying the traditional HP-filter to include just a lagged output gap as explanatory variable (what BDJ calls the dynamic HP-filter), the estimated coefficient reaches the upper boundary of 0.95 . The first panel of Figure 2 shows that there is very little difference in the point estimates between the traditional static HP-filter and the dynamic version. However, the two estimates do result in vastly different estimates of the precision of the estimated output gaps. Allowing for dynamics in the output gap gives rise to confidence bands that are much wider than under the simple static version (discussed in more detail below).

Looking at the other explanatory variables, it is clear from Table 1 that, as is the case in BDJ, financial factors do contain important information on business cycle fluctuations. The coefficients on real credit and property price growth are relatively large and highly significant. On the other hand, the coefficient on the real interest rate is much smaller and also less significant. This suggests that financial factors might do a better job of explaining business cycle fluctuations than interest rates. Figure 2 confirms that both credit and property prices modify the estimated output gaps considerably, especially in the second half of the 2000s. Interestingly, financial variables only start impacting the estimated output gap in a meaningful way in the early and mid-1980s in the wake of financial liberalisation $^{13}$.

\footnotetext{
${ }^{13}$ See Aron and Muellbauer (2011) for a more detailed exposition the financial liberalisation that took place in the early 1980s and its consequences for credit and property markets.
} 
Figure 2: Output gaps
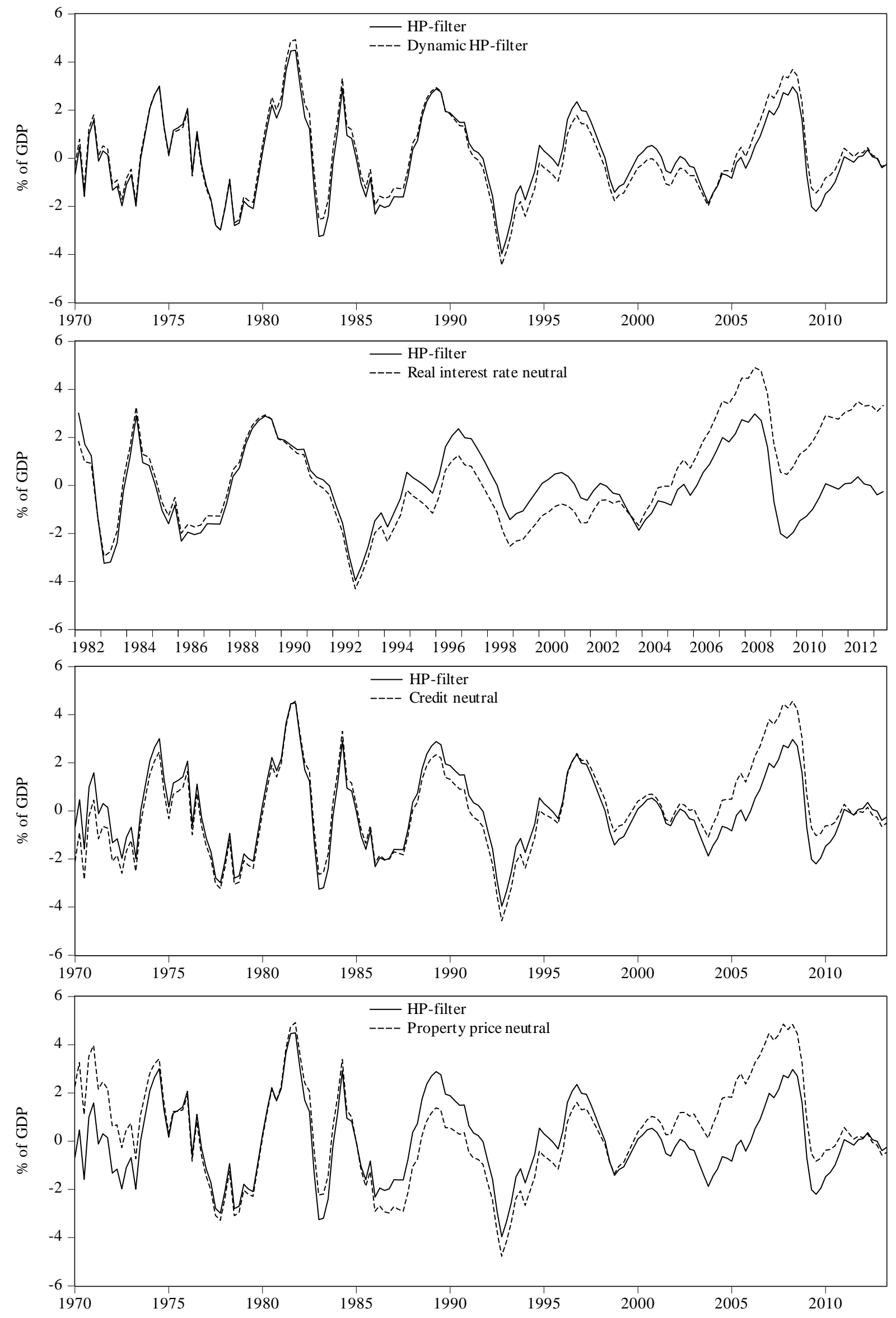
In general, the finance augmented output gap estimates are larger during the boom years in the latter half of the 2000s. As discussed in BDJ, these results are intuitive. Incorporating information on the financial cycle leads to estimates of sustainable output that also take into account the degree to which the financial sector is facilitating economic activity. In a boom phase, it would be expected that incorporating financial sector information should result in in lower estimates of sustainable output as the surge in credit availability artificially and temporarily boosts actual output relative to potential (resulting in a larger or more positive output gap). In the bust phase, the opposite would apply estimates of potential output are expected to be higher as credit constraints restrain economic activity to below potential (resulting in a smaller or more negative output gap).

When estimating the full model, which includes all three explanatory variables, the real interest rate is wholly dominated by the other financial variables. Because of this, model (5) in Table 1 is estimated by including only credit and property prices ${ }^{14}$. The coefficient on real credit growth remains relatively large and significant, while property prices have a smaller effect when included alongside real credit growth than was the case for the individually estimated equations. The fact that credit availability might influence demand for housing (and hence property prices) implies that some of the effects of property prices are implicitly captured in the evolution of real credit.

Figure 3 gives a visual representation of the final ex post finance-neutral output gap (shaded areas represent official downswings as published by the SARB). The estimated finance-neutral output gap matches the official narrative quite closely. However, the estimated gap is much larger compared to the HP-filter during the financial boom years, reflecting the strong credit and house price growth experienced during that time. Again, the effects of including financial market variables only become apparent in the period following financial market liberalisation.

Figure 3: Full specification

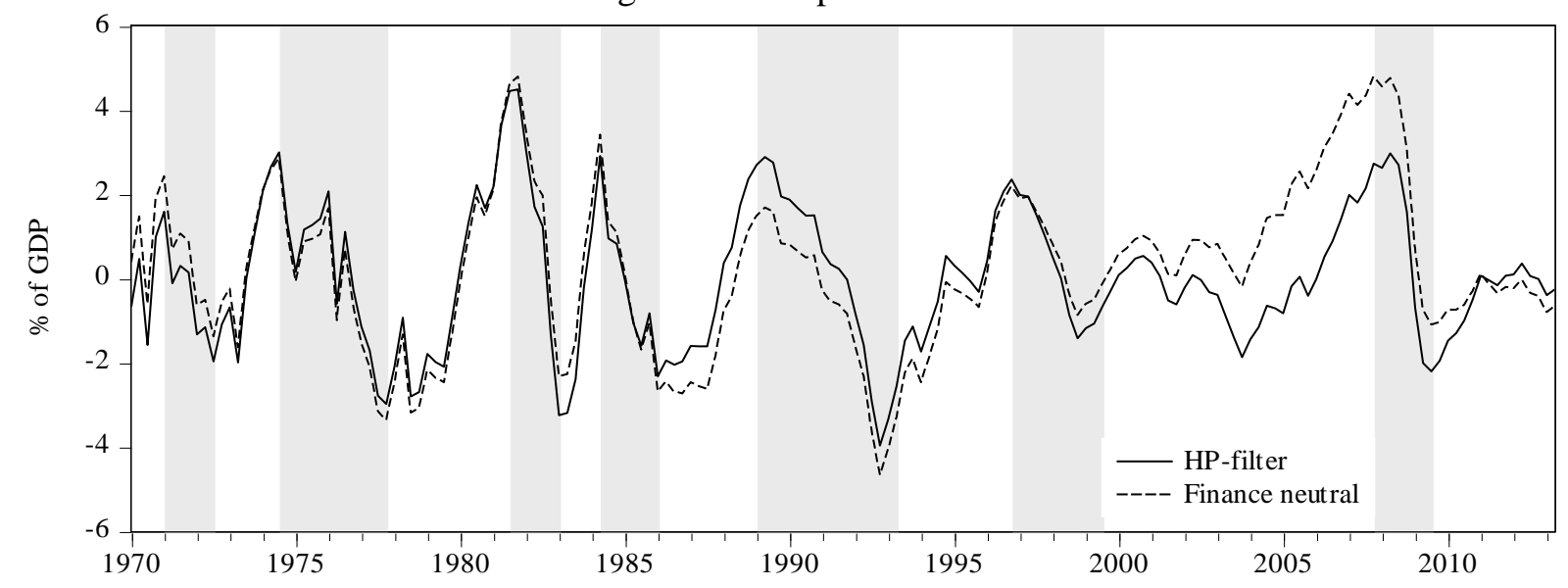

\subsection{Evaluation}

Results so far have shown that financial cycle variables can add valuable insights into the evolution of the cyclical component of output in South Africa. However, this in itself does not automatically justify the inclusion of said variables in the estimation of potential output. A more thorough

\footnotetext{
${ }^{14}$ The model estimated in this paper is linear in nature. BDJ estimate a non-linear version by estimating a threshold model for the deviations in credit and property price growth form their long-term trends. However, the results do not differ substantially from the simple linear model. As such, attention is restricted to the linear model. Future research could attempt to incorporate non-linearities in the framework.
} 
investigation of the performance of the model (both in terms of statistical precision and real-world applicability) is warranted.

\section{Statistical precision}

To evaluate the statistical precision of the estimates, confidence intervals are constructed and compared to those obtained from the dynamic HP-filter (model (1) in Table 1). As explained in BDJ, the dynamic HP-filter is used for comparative purposes because one needs to take into account the underlying persistence in the output gap variable in order to construct reliable confidence intervals. Failure to account for underlying persistence might result in confidence bands that are too narrow. For example, the model in (2) suggests that the output gap is simply a normally distributed, serially uncorrelated error. However, the high parameter estimate for the lagged dependent variable in model (1) in Table 1 suggests that the output gap is highly persistent and that (2) is misspecified. This misspecification would not be reflected in the associated confidence bands and results in intervals that are deceptively narrow. At the very least the underlying (near unit-root) persistence needs to be incorporated when constructing confidence bands (Borio et al, 2013a).

Keeping that in mind, Figure 4 plots the $95 \%$ confidence bands for the output gaps obtained from the dynamic HP-filter and model (5) in Table 1.

Figure 4: Statistical precision
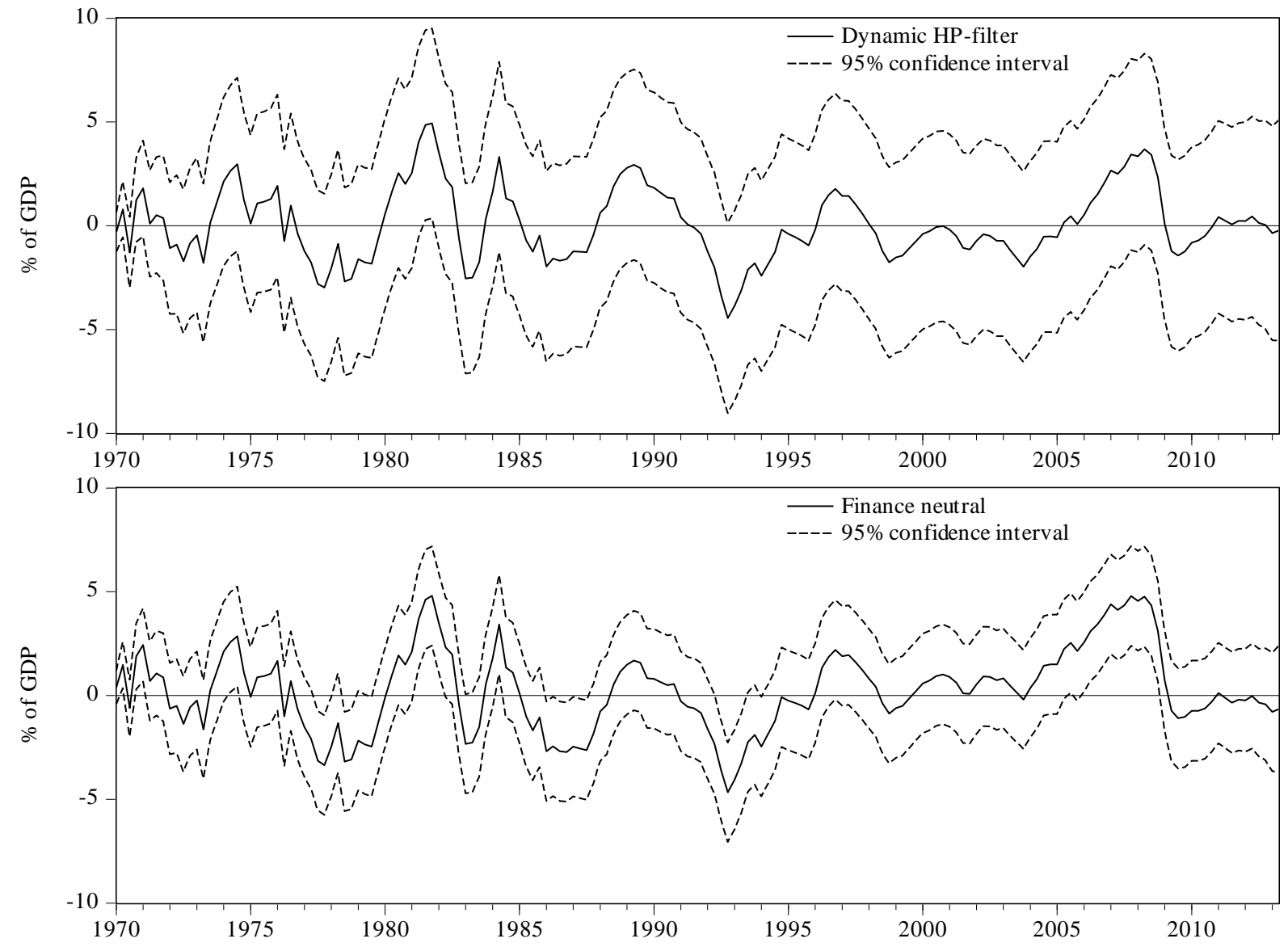

It is clear from Figure 4 that incorporating financial variables results in considerably more precise estimates (in a statistical sense) of the output gap. While still quite wide, the size of the confidence band is almost halved - from \pm 4.40 to \pm 2.36 . Additionally, in contrast to the dynamic HP-filter, the bands are narrow enough to produce output gap estimates that are statistically different from zero. 


\section{Real-time reliability}

As mentioned before, a major shortcoming of traditional measures of the output gap is the unreliability of real-time estimates. Up to now, the estimates presented have been based on the full sample, i.e. output gap estimates have been ex post. An important question is how robust the financeneutral estimates of the output gap are in real-time. As a starting point, Figure 5 presents the real-time and ex post estimates of the three different output gaps from 2000Q1 to 2013Q2 (all expressed as percentage of real GDP). As can be seen from the figure, the real-time finance-neutral output gap follows the ex post estimate much more closely than is the case for the other estimators. This is especially true in the financial boom years where traditional estimates suggest a much smaller output gap in real time than emerged ex post.

Figure 5: Ex post and real-time estimates
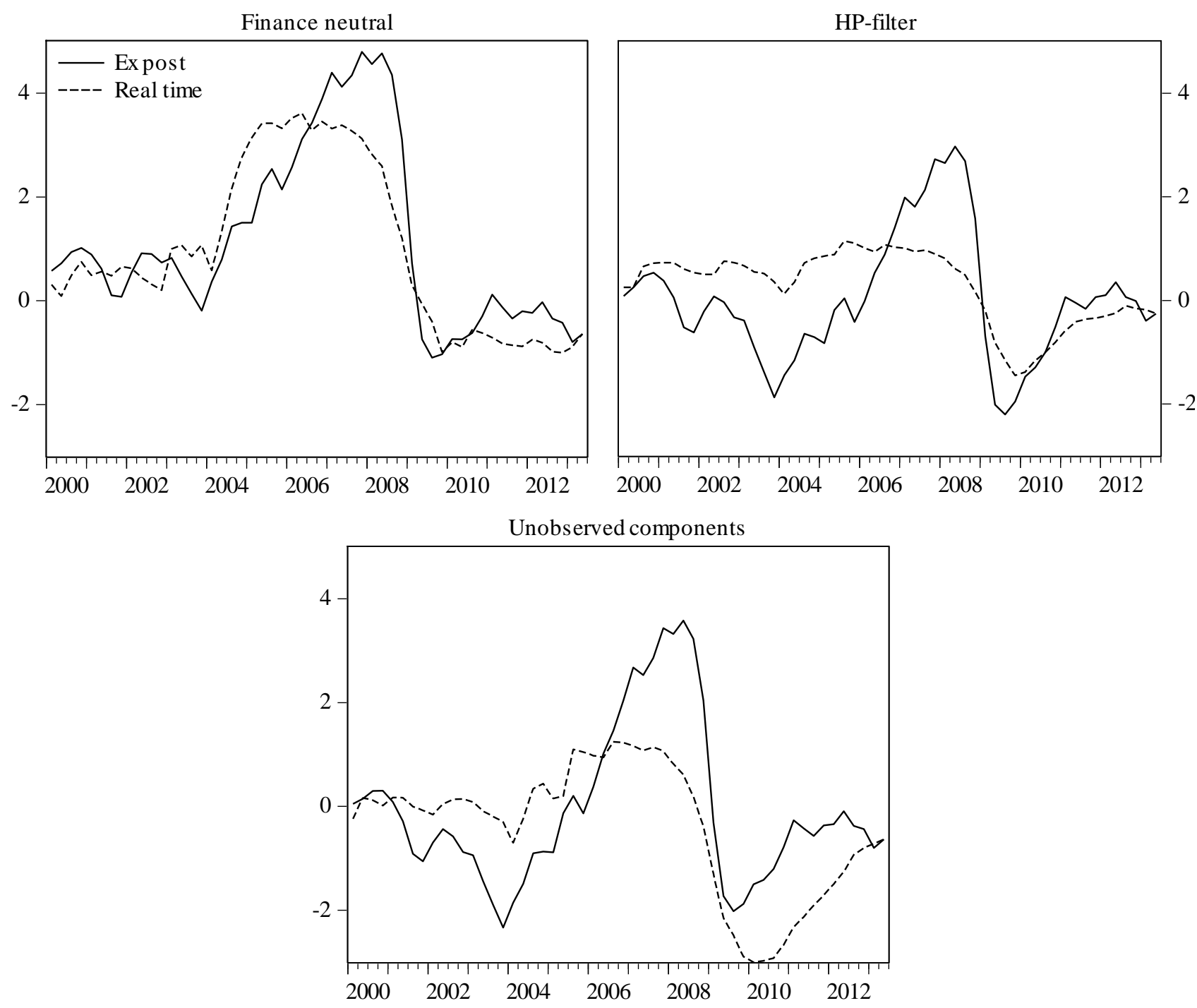

To get a more precise notion of how closely the real-time and ex post gaps track each other, the mean difference between the two measures (in absolute terms) is divided by the standard deviation of the ex post gap in order to obtain a measure of the average error per percentage movement in the output gap. This number equals $0.40,0.70$ and 0.72 for the finance-neutral, HP-filter and UC gaps respectively. These findings imply that incorporating financial cycle information in the estimation of output gaps 
results in estimates that are less vulnerable to the well-known end-point problems of the traditional HP-filter, while also potentially proving more reliable for policy making.

\section{Informing monetary policy}

The global financial crisis and its aftermath have reignited the debate on how best to incorporate financial stability concerns in the formulation of monetary policy. One way is to respond directly to proxies for financial imbalances. This could be accomplished through incorporating a term that reflects underlying financial conditions directly into central banks' loss functions (e.g. Woodford, 2012; Naraidoo and Raputsoane, 2013). An alternative is to base policy on an output gap measure that incorporates information on the financial cycle. The finance-neutral output gap proposed in BDJ and applied in this paper is an example of the second approach.

Figure 6 compares the behaviour of the policy rate based on the real-time finance-neutral, HP-filter and UC output gaps to each other and to the actual policy rate as set by the SARB.

Figure 6: Policy rate and Taylor rules
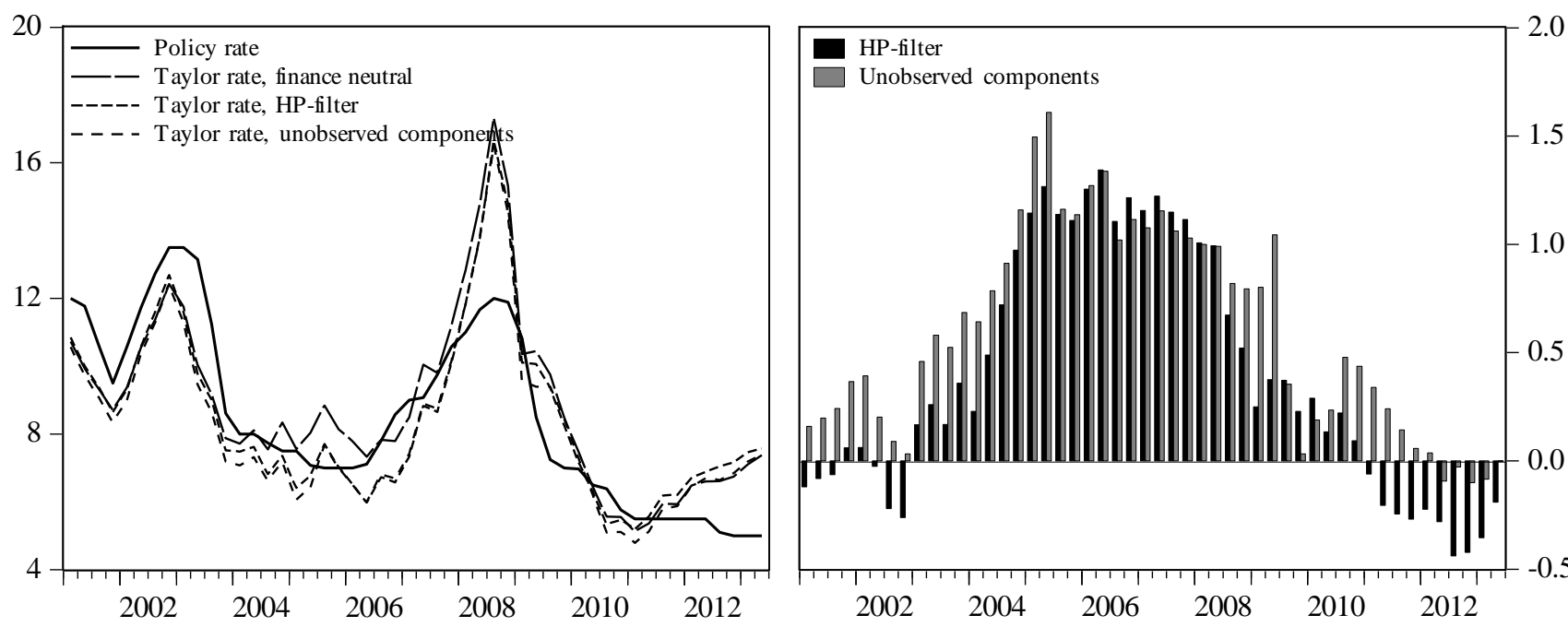

As in BDJ, a simple standard version of the Taylor (1993) rule is used. The rule is given by

$$
i_{t}^{*}=r^{*}+\pi^{*}+1\left(\pi_{t}-\pi^{*}\right)-0.5\left(y_{t}-y_{t}^{*}\right)
$$

where $i_{t}$ is the policy rate, $r^{*}$ is the equilibrium real interest rate, $\pi^{*}$ is the SARB's inflation target, $\pi_{t}$ is the inflation rate and $y_{t}-y_{t}^{*}$ is the output gap ${ }^{15}$. As discussed in BDJ, when interpreting the results it is important to note that the actual level of the implied policy rates should not be taken at face value as the assumption regarding the equilibrium real exchange rate is purely illustrative. The precise value assigned to $r^{*}$ is not central to the exercise: given that the focus is on the difference between the policy rates implied by the different output gaps, the actual level of the policy rate is not overly important. The value of the equilibrium real interest rate only affects the constant term in (6) and not the implied differences.

The results for South Africa mirror those obtained for the US, UK and Spain in BDJ. The financeneutral output gap would have called for considerably higher interest rates (i.e. tighter monetary

\footnotetext{
${ }^{15}$ Steinbach et al (2009) and Naraidoo and Raputsoane (2013) are used to calibrate the parameters on the output and inflation gaps; $r^{*}$ is set equal to 2.5 (based on the mean ex post real interest rate for the period 1981 to $2013) ; \pi^{*}$ is set equal to the mid-point of the SARB inflation target range, namely 4.5.
} 
policy) during the financial boom years compared with other estimates. The Taylor rates implied by the finance-neutral measure would have been around 1 percentage point higher on average between 2003 and 2007 (second panel in Figure 6). This is to be expected given that the real-time financeneutral output gap estimate was much more positive during this period compared to the estimates obtained from the HP-filter and UC models.

As mentioned in BDJ, the results do not imply that interest rates should bear the full burden of leaning against the build-up of financial imbalances. Rather, it is a combination of monetary, fiscal and regulatory measures that should be responsible for maintaining financial stability. The results do, however, illustrate that the finance-neutral measure of the output gap manages to capture the role of financial factors in influencing economic activity and should be incorporated into the broader information set of policymakers (Borio et al, 2013a).

\section{Concluding remarks}

Potential output is most often associated with some concept of sustainable factor utilisation and is often linked to inflation developments. However, recent history has shown that output can be on an unsustainable path while inflation remains low and stable as financial imbalances build up.

The approach followed in BDJ and applied here to South Africa attempts to capture the informational content that financial variables have for the cyclical component of output. The traditional HP-filter is extended to incorporate information on the financial cycle, in particular credit and property prices. Estimation results show that including financial cycle information (as captured by the behaviour of credit and property prices) results in output gaps that are estimated more precisely and are more robust to data revisions and the arrival of new data points (i.e. estimated output gaps are more robust in real time), while also reflecting the impact of financial variables on economic activity. Given the encouraging preliminary results, the research could be extended by, for example, investigating a wider range of financial sector variables and/or incorporating non-linearities into the estimation framework.

The apparent importance of financial variables in explaining business cycle fluctuations and the realtime robustness of the estimates obtained in this paper suggest that the finance-neutral output gap seems to represent a more appropriate measure on which to base monetary policy decisions than the traditional inflation-neutral measures prevalent in the literature. 


\section{Appendix A: Data definitions and sources}

$y_{t}=\log$ real seasonally adjusted GDP. Source: SARB Quarterly Bulletin

$i_{t}=$ nominal 91-day Treasury bill rate Source: SARB Quarterly Bulletin

$p_{t}=\log$ consumer price index. Source: Statistics South Africa

$c r_{t}=\log$ real credit extended to the domestic private sector. Source: SARB Quarterly Bulletin

$p p_{t}=\log$ real residential property price index, deflated by the CPI. Source: ABSA House Price Index 


\section{Appendix B: HP-filter and Unobserved Components}

\section{HP-filter}

The HP-filter assumes that the GDP series can be decomposed into a trend or growth component, $g_{t}$, and a cyclical component, $c_{t}$ :

$$
y_{t}=g_{t}+c_{t}
$$

In order to obtain the cyclical component, $g_{t}$ is chosen to minimise:

$$
\left\{g^{t}\right\}_{t=0}^{T+1}=\operatorname{argmin} \sum_{t=1}^{T}\left\{\left(y_{t}-g_{t}\right)^{2}+\lambda\left[\left(g_{t+1}-g_{t}\right)-\left(g_{t}-g_{t-1}\right)\right]^{2}\right\}
$$

In the equation above, $\lambda$ is the smoothing parameter and determines how smooth the trend will be by penalising variation in its growth rate. Hodrick and Prescott (1997) recommended a value of $\lambda=$ 1600 for quarterly data.

\section{Unobserved Components (UC)}

The UC model decomposes output into a trend, cycle and irregular component:

$$
y_{t}=u_{t}+v_{t}+\varepsilon_{t}
$$

where $u_{t}$ is the trend, $v_{t}$ is a second-order autoregressive cyclical component and $\varepsilon_{t}$ is the normally distributed irregular component with mean zero and variance $\sigma_{\varepsilon}^{2}$. The trend component is specified as the linear model:

$$
\begin{gathered}
u_{t}=u_{t-1}+\beta_{t-1}+\eta_{t}, \quad \eta_{t} \sim \operatorname{IID}\left(0, \sigma_{\eta}^{2}\right) \\
\beta_{t}=\beta_{t-1}+\epsilon_{t}, \quad \epsilon_{t} \sim \operatorname{IID}\left(0, \sigma_{\epsilon}^{2}\right)
\end{gathered}
$$

where $\beta_{t}$ is the slope. The disturbances $\varepsilon_{t}, \eta_{t}$ and $\epsilon_{t}$ are mutually uncorrelated. Maximum likelihood estimation is normally undertaken using the Kalman filter. 


\section{References}

Aikman, D., Haldane, A. and Nelson, B. (2011). Curbing the credit cycle. Speech delivered at Columbia University Center on Capitalism and Society Annual Conference, New York.

Akinboade, O.A., Krige, F. and Wambach, E. (2004). The Output Costs during Episodes of Disinflation in South Africa. Paper presented at the Ninth Annual Conference on Econometric Modelling for Africa, 30 June to 2 July 2004, Cape Town.

Alessi, L. and Detken, C. (2009). Real time early warning indicators for costly asset price boom/bust cycles: A role for global liquidity. ECB Working Paper, No 1039.

Aron, J. and Muellbauer, J. (2011). Wealth, Credit Conditions and Consumption in South Africa. Paper Prepared for the Special IARIW-SSA Conference on Measuring National Income, Wealth, Poverty, and Inequality in African Countries. Cape Town, South Africa. September 28 - October 1, 2011.

Arora, V. and Bhundia, A. (2003). Potential Output and Total Factor Productivity Growth in PostApartheid South Africa. IMF Working Paper, WP/03/178.

Benes, J. and N'Diaye, P. (2004). A Multivariate Filter for Measuring Potential Output and the NAIRU: Application to the Czech Republic. IMF Working Paper, WP/04/45.

Beveridge S. and Nelson, C.R. (1981). A new approach to the decomposition of economic time series into permanent and transient components with particular attention to measurement of the business cycle. Journal of Monetary Economics, 7.

Blanchard, O.J. and D. Quah (1989). The dynamic effect of aggregate demand and supply disturbances. American Economic Review, 79.

Borio, C. and Lowe, P. (2002). Asset prices, financial and monetary stability: Exploring the Nexus. BIS Working Papers, No 114.

Borio, C. (2012). The financial cycle and macroeconomics: what have we learnt? BIS Working Papers, No 395.

Borio, C., Disyatat, P. and Julselius, M. (2013a). Rethinking potential output: Embedding information about the financial cycle. BIS Working Papers, No 404.

Borio, C., Disyatat, P. and Juselius, M. (2013b). A new approach to measuring potential output: avoiding pitfalls when incorporating economic information. Mimeo, forthcoming as BIS Working Papers.

Cerra, V. and Saxena, S.C. (2000). Alternative Methods of Estimating Potential Output and the Output Gap: An Application to Sweden. IMF Working Paper, WP/00/59.

Clarida, R. and Gali, J. (1994). Sources of real exchange rate fluctuations: how important are nominal shocks? Proceedings, Federal Reserve Bank of Dallas, April.

Cotis J.-P., Elmeskov, J. and Mourougane, A. (2005). Estimates of potential output: benefits and pitfalls from a policy perspective. In L. Reichlin (ed.), Euro area business cycle: stylised facts and measurement issues, CEPR. 
Drehmann, M., Borio, C. and Tsatsaronis, K. (2011). Anchoring countercyclical capital buffers: the role of credit aggregates. International Journal of Central Banking, 7(4).

Du Plessis, S., Smit, B.W. and Sturzenegger, F. (2007). Identifying Aggregate Supply and Demand Shocks in South Africa. Stellenbosch Economic Working Papers, 11/2007.

Du Toit, C.B., Van Eyden, R. and Ground, M. (2006). Does South Africa have the potential capacity to grow at 7 per cent?: A labour market perspective. University of Pretoria, Department of Economics Working Paper Series, WP 2006-03.

Gibbs, D. (1995). Potential Output: Concepts and Measurement. Labour Market Bulletin, 1995:1.

Harvey, A. C. (1992). Forecasting, Structural Time Series Models and the Kalman Filter. Cambridge University Press: Cambridge.

Harvey, A.C. and Jaeger, A. (1993). Detrending, Stylized Facts and the Business Cycle. Journal of Applied Econometrics, 8.

Hodrick, R. and Prescott, E.C. (1997). Postwar U.S. Business Cycles: An Empirical Investigation. Journal of Money, Credit, and Banking, 29 (1).

Kaiser, R. and Maravall, A. (1999). Estimation of the business cycles: A modified Hodrick-Prescott filter. Spanish Economic Review, 1, 175206.

Kalman, R.E. (1960). A new approach to linear filtering and prediction problems. Journal of Basic Engineering, 82(1).

Konuki, T. (2008). Estimating Potential output and the Output Gap in Slovakia. IMF Working Paper, WP/08/275.

Kramer, J. and Farrell, G. (2013). The reliability of South African real-time output gap estimates. ERSA Working Paper, No x, Forthcoming.

Mc Morrow, K. and Roeger, W. (2001). Potential Output: Measurement Methods, "New" Economy Influences and Scenarios for 2001-2010 - A comparison of the EU-15 and the US. European Economy - Economic Papers 150, Directorate General Economic and Monetary Affairs, European Commission.

Meade, J.E. (1978). The Meaning of Internal Balance. Economic Journal, Vol. 88(351).

Mise, E., Kim, T-H. and Newbold, P. (2003). The Hodrick-Prescott Filter at Time Series Endpoints. University of Nottingham Economics Discussion Paper 03/08.

Mise, E., Kim, T-H. and Newbold, P. (2005). On the sub-optimality of the Hodrick-Prescott Filter. Journal of Macroeconomics, 27.

Naraidoo, R. and Raputsoane, L. (2013). Financial Markets and the response of Monetary Policy to Uncertainty in South Africa. University of Pretoria, Department of Economics Working Papers Series, WP 2013-10.

Nelson, C. and Plosser, C.I. (1982). Trends and random walks in macroeconomic series. Journal of Monetary Economics, 10. 
Smit, B. W. and Burrows, L. (2002). Estimating Potential Output and Output Gaps for the South African Economy. Stellenbosch Economic Working Papers, 5/2002.

St-Amant, P. and van Norden, S. (1997). Measurement of the Output Gap: A Discussion of Recent Research at the Bank of Canada. Technical Reports 79, Bank of Canada.

Steinbach, R., Mathuloe, P. and Smit, B. (2009). An open economy New Keynesian DSGE model of the South African economy. SARB Working Paper, WP/09/01.

Vetlov, I., Hledik, T., Jonsson, M., Kucsera, H. and Pisani, M. (20110. Potential Output in DSGE Models. ECB Working Paper Series, No 1351.

Woodford, M. (2012): Inflation targeting and financial stability. NBER Working Paper, No 17967. 